\title{
Assessment of oral hygiene, periodontal status, dentition status and treatment needs among detainees in juvenile detention centres, of Madhya Pradesh
}

\begin{abstract}
Context: The purpose of this study was to assess the Oral Hygiene, Periodontal Status, Dentition Status and Treatment Needs among the detainees in juvenile detention centres of Madhya Pradesh

Settings and design: Cross sectional survey

Methods and material: A survey was scheduled to spread over a period of 6 months from February 2015 to July 2015. All the children present in the detention centres on the day of survey will be examined. Data will be collected using a self administered proforma which will be further divided into two parts. First part will record the demographic details, oral hygiene practices, length of stay, first offenders or repeat offenders, educational level, Dental care utilization and tobacco usage. Second part includes Clinical examination which will be performed on the seated patients by a single trained and calibrated examiner under adequate illumination
\end{abstract}

Statistical analysis used: All the collected data of the study will be coded and analysed using the latest version of a statistical package for social sciences (SPSS). Various tests for statistical analysis include Arithmetic mean, standard deviation, Analysis of variance (ANOVA), Student t-test, Chi-square test. Multiple stepwise linear and logistic regression analysis will be used to determine the predictors of oral hygiene, periodontal status and dental caries.

Results: Mean DMFT values in all the age groups were quite low. An important finding of our study was that most of the detainees were smokeless tobacco users. Difference in OHI-S scores among the different age groups was statistically significant $(\mathrm{p}=0.001)$. Significant statistical difference was found between education and oral hygiene status $(\mathrm{p}=0.001)$. CPI scores and education was found to be significant in present study $(\mathrm{p}=0.001)$.

Conclusion: This study has confirmed that there is a need for organized preventive and curative care for the juvenile detainees of Madhya Pradesh.

Keywords: juvenile detainee, oral hygiene
Volume 9 Issue 5 - 2018

\author{
Petkar Pallavi,' Amith HV, ${ }^{2}$ Vinayak Kamath, ${ }^{3}$ \\ Bhanupriya Thakur ${ }^{4}$ \\ 'Dental Surgeon, Govt. District Nehru Hospital, India \\ 2Deptartment of Public Health Dentistry, People's University, \\ India \\ ${ }^{3} \mathrm{KLE}$ Institute of Dental Sciences, KLE University, India \\ ${ }^{4}$ Deptartment of Public Health Dentistry, Guru Gobind Dental \\ College, India
}

Correspondence: Pallavi Petkar, MDS, Dental Surgeon, Govt. District Nehru Hospital, 234, E Block Vaishno Appt. Surendra Place Bhopal, 462026, Madhya Pradesh, India, Tel 07552485373, Email dr.pallavi.pekkar@gmail.com

Received: April 27, 2017| Published: October 17, 2018

\section{Introduction}

A juvenile is a person, below 18years of age. ${ }^{1}$ A child is a part of society in which he lives. Due to his immaturity, he is easily motivated by what he sees around him. It is his environment and social context that provokes his actions. 'Delinquent juvenile or juvenile in conflict with law' means a juvenile who is alleged to have committed an offence. The rising prevalence of juvenile criminal offence is currently a major concern throughout the world. ${ }^{1}$ Research in prison health has found an immense number of health problems to be elevated among inmates. Prisoners experience disproportionately high levels of both physical and mental health problems, including infectious diseases, chronic medical conditions, and psychological disorders. ${ }^{2}$ The prisoners are a psychologically, socially, morally and economically affected group which make them neglect their general as well as oral health. ${ }^{3}$ Many prisoners enter prison with poor oral health, requiring emergency treatment. This may be due to limited knowledge about good oral health practices. Excessive alcohol consumption, particularly spirits, and tobacco use increase the prevalence and severity of periodontal disease and are by far the greatest risk factors for oral cancer. ${ }^{4}$ There is currently no standardised system of assessment and prioritisation of the dental needs of prisoners. ${ }^{5}$

The prisoners in jail have a different life style. Regular dental care and daily oral hygiene are not a routine component of their life style. However, Clare ${ }^{6}$ reported a substantial reduction in the prevalence of dental caries and an improvement in periodontal health among prisoners who had served continually for 3years in prison. A study among remand prisoners in HMP Brixton, London, revealed that majority of them $(73 \%)$ had visited a dentist during the last year. Their most recent dental visit was in prison $(54 \%){ }^{7}$ Results of a study among the Prison Inmates of Nellore District in Andhra Pradesh revealed that the inmates were suffering from periodontal. and the prevalence of dental caries was nearly $78 \%$ indicating the need for high importance of treatment of dental caries among prison inmates. This study demonstrates that the standard of oral health care for prison inmates is low. ${ }^{8}$ A survey among inmates in central jail of Karnataka, India showed that, prevalence of dental caries was $97.5 \% .{ }^{5}$ Sanjay Kumar Singh reported that overall $77.8 \%$ of inmates of Lucknow city had decayed teeth. This study found a high prevalence of dental 
caries among the prison populations. ${ }^{9}$ Among inmates at Hong Kong's elderly detention centre, the prevalence of oral disease was high and the impact of oral health on their life quality was substantial. ${ }^{10}$ Among Jaipur inmates, most of them had poor periodontal conditions and $79 \%$ inmates had dental caries with mean DMFT of $4.79 .{ }^{11}$ Very few studies have been conducted in India regarding oral health status of Juveniles in detention centre. Hence, this study was designed to assess the Oral Hygiene status, Periodontal Status, Dentition Status and Treatment Needs among the detainees in juvenile detention centres of Madhya Pradesh state.

\section{Material and method}

The present descriptive, cross-sectional study was conducted to assess Oral Hygiene, Periodontal Status, Dentition Status and Treatment Needs among the detainees in juvenile detention centres of Madhya Pradesh. A self administered proforma was used which was further divided into two parts. First part recorded the demographic details, oral hygiene practices, length of stay, and type of offenders, educational level, Dental care utilization and tobacco usage. Second part included clinical examination which was performed on the seated patients by a single trained and calibrated examiner under adequate illumination (ADA Type III). . The oral hygiene variables of each subject were assessed using the Simplified Oral Hygiene Index (OHI-S) of Greene and Vermillion (1964). The average individual debris and calculus scores were determined and added together to obtain the OHI-S for each subject. Based on the OHI-S score, oral hygiene status was categorized as good (0 to 1.2), fair (1.3 to 3 ) and poor (3.1 to 6.0). Ethical clearance was obtained from the ethical committee of Peoples College of Dental Sciences, Bhopal (Project code: 2014PHD04, Ref/ PCDS/AC/AD/8/2014/30). Written permission was obtained from Directorate Women empowerment department to conduct the survey in various juvenile centres of the Madhya Pradesh. Informed consent was also obtained from matrons of each juvenile detention centre.

Table I List of Juvenile detention centres in Madhya Pradesh

\begin{tabular}{lll}
\hline S. No & Juvenile Detention Centre & $\begin{array}{l}\text { Number of Detainees } \\
\text { examined }\end{array}$ \\
\hline I. & Vidisha & 7 \\
2. & Bhopal & 22 \\
3. & Narsinghpur & 11 \\
4. & Seoni & 29 \\
5. & Sagar & 14 \\
6. & Ujjain & 9 \\
7. & Jabalpur & 19 \\
8. & Betul & 19 \\
9. & Morena & 5 \\
I0. & Guna & 13 \\
II. & Gwalior & 10 \\
I2. & Indore & 19 \\
I3. & Chhatarpur & 14 \\
I4. & Khandwa & 20 \\
I5. & Rewa & 34 \\
16. & Ratlam & 23 \\
\hline
\end{tabular}

A pilot study was carried out in Bhopal Juvenile detention centre, mainly to assess the feasibility of study. Total 22 subjects were examined. Time taken to record proforma was 7-8 minute per detainee. There were 18 detention centres for juveniles throughout Madhya Pradesh. Approximately 400 inmates were housed in these centres in themonth of December 2013. The sample size was calculated using the online sample size calculator available from http://www. surveysystem.com/sscalc.htm. ${ }^{8}$ The sample required for a finite population of 400, a confidence interval of 4 and a confidence level of $95 \%$ was 240 , Almost all the juvenile detention centres of Madhya Pradesh were covered and 268 juvenile detainees present on the day of examination were examined. Age group of subjects were 5 year onward up to 20year. Prior permission to examine the detainees was obtained from appropriate authorities before starting the survey. A crosssectional study was conducted among detainees in juvenile detention centres of Madhya Pradesh. All the subjects present on the day of survey were included in study. Subjects who were uncooperative and systemically ill and subjects not willing to sign the informed consent were excluded. A survey was scheduled to spread over a period of 6months from February 2015 to July 2015. A detailed weekly and monthly schedule was prepared well in advance by informing and obtaining consent from authorities of respective study areas. Before conducting the study, training and calibration of examiner was done. Intra-examiner reliability was assessed using kappa statistics which was in range of $0.75-0.81$, showing a high degree of conformity in the observations. There were 18 Juvenile detention centres in Madhya Pradesh. Total 268 juvenile detainees were examined. Centre wise list of number of detainees present on the day of examination (Table 1).

\section{Statistical analysis}

The obtained data was coded and entered in Microsoft excel. Data were statistically analyzed by using SPSS (Statistical package for social sciences) software version 17. Descriptive statistics that included frequency and percentages were calculated for each of the categories. Fisher's exact test was used to determine the association between different variables under study like age, gender, education, education, length of stay, type of visit, oral hygiene practices. Mann Whitney $U$ test was used to determine mean DMFT, mean number of decayed, missing, filled teeth, mean number missing due to caries, missing due to any other reason and trauma teeth. Confidence interval was kept at $95 \% . \mathrm{P}<0.05$ was accepted as statistically significant and $\mathrm{p}<0.0001$ was set to be highly statistically significant.

\section{Results}

Descriptive statistics of Sociodemographic and general characteristics of the study population presented Table 2. Two hundred sixty eight juvenile detainees were interviewed and clinical examination performed in 16 juvenile detention centres of Madhya Pradesh; 255(95.1\%) were males and 13(4.9\%) were females. Most of the detainees i.e., $192(71.6 \%)$ were in the age group of 16 -20years, followed by $75(28 \%)$ in $11-15$ year age group, and $1(.4 \%)$ in 5 -10year age group. The education level varied among the juvenile detainees with majority of them having studied till high school $-133(49.6 \%)$, juvenile detainees who studied till primary school were $77(28.7 \%)$, those who studied till Senior secondary school were $18(6.7 \%)$ and $40(14.9 \%)$ were illiterate. Out of 268 inmates, $174(64.9 \%)$ were in detention centre for up to 2months, 28 (10.4\%) for up to 6months and 
$66(24.6 \%)$ for more than 6months. Most of the juvenile detainees $238(88.8 \%)$ were first time offenders, $24(9.0 \%)$ were second time offenders and only $6(2.2 \%)$ were in the category of having committed offence more than twice.

Table 2 Sociodemographic and general characteristics of the study population

\begin{tabular}{lll}
\hline Independent variables & Number & Percentage (\%) \\
\hline Gender & 255 & 95.1 \\
\hline Male & 13 & 4.9 \\
Female & & \\
\hline Age & 1 & 0.4 \\
\hline 5-10 years & 75 & 28.0 \\
II-15 years & 192 & 71.6 \\
16-20 years & & \\
\hline Highest education obtained & 77 & 28.7 \\
\hline Primary School & 133 & 49.6 \\
High School & 18 & 6.7 \\
Senior Secondary School & 40 & 14.9 \\
None & & \\
\hline Length Of Stay & 174 & 64.9 \\
\hline Up to 2 months & 28 & 10.4 \\
Up to 6 months & 66 & 24.6 \\
More than 6 months & & \\
\hline Type of Visit & 238 & 88.8 \\
\hline First Time & 24 & 9.0 \\
Second Time & 6 & 2.2 \\
More & & \\
\hline
\end{tabular}

Descriptive statistics of Oral hygiene practice of the study population presented Table 3. Majority of detainees i.e., 228(85.1\%) used tooth brush, 35(13.1\%) used finger and 5(1.9\%) subjects used Neem sticks for cleaning teeth. Out of 268 detainees 207(77.2\%) used tooth paste, $58(21.6 \%)$ used tooth powder and only $3(1.1 \%)$ used other materials for cleaning their teeth. Most of the juvenile detainees i.e., $207(77.2 \%)$ brushed their teeth once a day, 59(22.0\%) brushed twice a day, $1(0.4 \%)$ brushed occasionally and $1(0.4 \%)$ never brushed. Almost more than half of the juvenile detainees-154(57.5\%) brushed their teeth for up to 5minutes, $73(27.2 \%)$ brushed their teeth for 1-2minutes, and $41(15.3 \%)$ brushed their teeth for 3-4minutes. Almost all the juvenile detainees 260(97.0\%) used horizontal method for cleaning their teeth, except few who brushed their teeth by using combination $4(1.5 \%)$, vertical method of cleaning was followed by $3(1.1 \%)$, and circular by $1(.4 \%)$ subject. Majority of juvenile detainees $264(98.5 \%)$ were not using mouthwash, and only $4(1.5 \%)$ used mouthwash. Descriptive statistics of Personal Habits of the study population presented Table 4. Out of 268 juvenile detainees, 167(62.3\%) had smoked or chewed tobacco, and 101(37.7\%) had never taken tobacco in any form. The percentage of juvenile detainees who smoked was 46(17.2\%), and those who didn't were 222(82.8\%). The juvenile detainees who chewed tobacco were $123(45.9 \%)$, and those who didn't were $145(54.1 \%)$. Most of the juvenile detainees 231(86.2\%) had the habit of smoking for less than 1 month, $4(1.5 \%)$ smoked for 1 month to 6 months, $11(4.1 \%)$ smoked for 7 months to 12 months, and $22(8.2 \%)$ smoked for more than 12 months. Out of 268 juvenile detainees $84(31.3 \%)$ used smokeless tobacco for more than 12 months, $30(11.2 \%)$ had the habit for 7 months to 12 months, $35(13.1 \%$ ) of them for 1 month to 6 months, and only very few $6(2.2 \%)$ had the habit for less than 1 month. Most of juvenile detainees $-34(12.6 \%)$ smoked $1-5$ cigarettes per day, $6(2.3 \%)$ smoked 6-10 cigarettes per day, and 6(2.3\%) smoked 11-20 cigarettes per day. Majority of juvenile detainees $133(49.6 \%)$ had chewed 1-5 pouches per day, $12(4.5 \%)$ had chewed more than 6 pouches per day. It was found that $250(93.3 \%)$ juvenile detainees never visited a dentist previously and very few of them-18(6.7\%) visited dentist for treatment of their dental problem. Most of juvenile detainees $265(98.9 \%)$ had not received dental treatment before or during the imprisonment, and only few $3(1.1 \%)$ had received dental treatment. It was found that most of the juvenile detainees-194(72.4\%) had fair oral hygiene, $67(25.0 \%)$ had good oral hygiene, and only $7(2.6 \%)$ had poor oral hygiene. This was based on the highest CPI score. Most of them had calculus $230(85.8 \%), 2(.7 \%)$ had bleeding, $1(.4 \%)$ had pocket $4-5 \mathrm{~mm}, 2(.7 \%)$ had pocket $6 \mathrm{~mm}$ or more, and $33(12.3 \%)$ had healthy gingiva.

\begin{tabular}{|c|c|c|}
\hline Independent Variable & Number & Percentage (\%) \\
\hline \multicolumn{3}{|c|}{ Oral hygiene aid used for cleaning teeth } \\
\hline Tooth Brush & 228 & 85.1 \\
\hline Finger & 35 & 13.1 \\
\hline Others & 5 & 1.9 \\
\hline \multicolumn{3}{|c|}{ Material Used for Cleaning Teeth } \\
\hline Toothpowder & 58 & 21.6 \\
\hline Toothpaste & 207 & 77.2 \\
\hline Others & 3 & I.I \\
\hline \multicolumn{3}{|l|}{ Frequency of brushing } \\
\hline Once daily & 207 & 77.2 \\
\hline Twice daily & 59 & 22.0 \\
\hline Occasionally & I & 0.4 \\
\hline Never & I & 0.4 \\
\hline \multicolumn{3}{|l|}{ Duration of brushing } \\
\hline $1-2 \min$ & 73 & 27.2 \\
\hline $3-4 \min$ & 41 & 15.3 \\
\hline $5 \mathrm{~min}$ or more & 154 & 57.5 \\
\hline \multicolumn{3}{|c|}{ Method / Direction of Cleaning of teeth } \\
\hline Horizontal & 260 & 97.0 \\
\hline Vertical & 3 & I.I \\
\hline Circular & I & 0.4 \\
\hline Combination & 4 & 1.5 \\
\hline \multicolumn{3}{|l|}{ Use of Mouthwash } \\
\hline Yes & 4 & 1.5 \\
\hline NO & 264 & 98.5 \\
\hline
\end{tabular}

Descriptive statistics of Distribution of oral hygiene status of the subjects in relation to age, gender, education, length of stay and type of visit of the study population presented Table 5. The Oral Hygiene Index scores for age group up to 15 years was good for $11(14.5 \%)$ and $65(85.5 \%)$ had fair and poor oral hygiene. In age group of 16 -20years 56(29.2\%) had good oral hygiene while 136(70.8\%) had fair and poor oral hygiene. The difference in OHI-S scores among 
the different age groups was statistically significant $(\mathrm{p}=0.01)$. Most of detainees who had education more than primary level had a Good score of OHI-S(35.1\%) compared to detainees who had education up to primary level(12.0\%), while Fair and Poor score were more in detainees who had education up to primary level 103(88.0\%). When education was compared, there was significant statistical difference between all the categories with $p$ value $<0.001$.

Table 4 Personal habits

\begin{tabular}{|c|c|c|}
\hline Independent Variable & Number & Percentage (\%) \\
\hline \multicolumn{3}{|c|}{ Have you ever Smoked or Chewed Tobacco } \\
\hline Yes & 167 & 62.3 \\
\hline No & 101 & 37.7 \\
\hline \multicolumn{3}{|l|}{ Use of Smoked tobacco } \\
\hline Yes & 46 & 17.2 \\
\hline No & 222 & 82.8 \\
\hline \multicolumn{3}{|l|}{ Use of Smokeless tobacco } \\
\hline Yes & 123 & 45.9 \\
\hline No & 145 & 54.1 \\
\hline \multicolumn{3}{|l|}{ Duration of Smoking habit } \\
\hline Less than I Month & 231 & 86.2 \\
\hline I Month to 6 Month & 4 & 1.5 \\
\hline More than 6 months to 12 Month & 11 & 4.1 \\
\hline More than 12 Month. & 22 & 8.2 \\
\hline \multicolumn{3}{|c|}{ Duration of Smokeless tobacco use } \\
\hline Less than I Month & 6 & 2.2 \\
\hline I Month to 6 Months & 35 & 13.1 \\
\hline More than 6 months to 12 Months & 30 & 11.2 \\
\hline More than 12 Month. & 84 & 31.3 \\
\hline \multicolumn{3}{|l|}{ Frequency of Smoking } \\
\hline I-5/day & 34 & 12.6 \\
\hline $6-10 /$ day & 6 & 2.3 \\
\hline II-20/ day & 6 & 2.3 \\
\hline Total & 268 & 100.0 \\
\hline \multicolumn{3}{|c|}{ Frequency of Smokeless tobacco use } \\
\hline I-5/ day & 133 & 49.6 \\
\hline$>6 /$ day & 12 & 4.5 \\
\hline Total & 268 & 100.0 \\
\hline \multicolumn{3}{|l|}{ Visit to dentist previously } \\
\hline Yes & 18 & 6.7 \\
\hline No & 250 & 93.3 \\
\hline \multicolumn{3}{|l|}{ Received dental treatment } \\
\hline Yes & 3 & 1.1 \\
\hline No & 265 & 98.9 \\
\hline \multicolumn{3}{|l|}{ Oral Hygiene Status (OHI-S) } \\
\hline Good & 67 & 25.0 \\
\hline Fair & 194 & 72.4 \\
\hline Poor & 7 & 2.6 \\
\hline
\end{tabular}

Highest CPI Score
Table Continued...

$\begin{array}{lll}\text { Healthy } & 33 & 12.3 \\ \text { Bleeding } & 2 & 0.7 \\ \text { Calculus } & 230 & 85.8 \\ \text { Pockets } 4-5 \mathrm{~mm} & \mathrm{I} & 0.4 \\ \text { Pockets } 6 \mathrm{~mm} \text { or more } & 2 & 0.7\end{array}$

Descriptive statistics of Distribution of oral hygiene status of the subjects in relation to oral hygiene practices of the study population presented in Table 6. Only duration of brushing was found to be significantly associated with $\mathrm{OHI}-\mathrm{S}$ scores, with $\mathrm{p}$ value 0.05 . Brushing Aid used for cleaning teeth , material used for cleaning teeth, frequency of brushing, \& method of brushing were not significantly associated with oral hygiene scores. Descriptive statistics of Periodontal status in relation to age groups of the study population presented in Table 7. By applying Mann Whitney U test, it was found that there was no significant difference between periodontal status and the age groups with $\mathrm{p}$ value 0.49 for healthy, 0.26 for bleeding, 0.92 for calculus, 049 for shallow pockets and 0.50 for deep pockets. Descriptive statistics of DMFT scores in relation to age groups of the study population presented in Table 8. By applying Mann Whitney $\mathrm{U}$ test, it was found that there was no significant difference between DMFT scores and age groups with $\mathrm{p}$ values 0.85 for decayed, 0.93 for missing, 0.52 for filled and 0.87 total DMFT. Descriptive statistics of Distribution of missing due to caries, missing due to any other reason and trauma in relation to age groups of the study population presented in Table 9. By applying Mann Whitney U test, it was found that there was no significant difference between missing due caries, missing due to any reason and trauma across the age groups with $p$ value $0.677,0.84,0.56$ respectively. Descriptive statistics of Distribution of juvenile detainees according to treatment need of the study population presented in Table 10 . Out of 268 subjects, $86(32.1 \%)$ required no treatment, while $182(67.9 \%)$ required treatment. Sixty three $(23.5 \%)$ of juveniles required one surface restoration. Two or more surface restoration was required by $13(4.9 \%)$. None of them needed crown, veneer or laminates. Fifteen (5.6\%) of juveniles needed pulp care / restoration. Extractions were needed in case of $7(2.6 \%)$ juveniles, need for other care was found in $8(3.0 \%)$ of the subjects. Descriptive statistics of periodontal status assessed by community periodontal index in relation to age, gender, education, length of stay and type of visit of the study population presented in Table 11. By applying Fisher's exact test it was found that there was a significant difference between age and periodontal status with $p$ value 0.01 . By applying Fisher's exact test it was found that there was a significant difference between level of education and periodontal status with $\mathrm{p}$ value 0.001 . Descriptive statistics of Periodontal status of the subjects assessed by Community Periodontal Index in relation to Oral Hygiene Practices of study population presented in Table 12. By applying Fisher's exact test it was found that Community Periodontal Index and Oral Hygiene Practices were not significantly associated. Descriptive statistics of Mean(SD) oral hygiene status of juveniles in detention centre in relation to Gender, Age, Education, Length Of Stay, Type Of Visit, Brushing Aids Used for Cleaning Teeth, Material Used for Cleaning Teeth, Frequency of Brushing and Method of Brushing of the study population presented in Table 13. By applying Mann Whitney U test it was found that there was a significant difference between level of education and oral hygiene status with $\mathrm{p}$ value 0.001 . By applying Mann Whitney $U$ test it was found that there was a significant difference between duration of brushing and oral hygiene status with $\mathrm{p}$ value 0.03 . 
Table 5 Distribution of oral hygiene status of the subjects in relation to age, gender, education, length of stay and type of visit ${ }^{*} p<0.05$ statistically significant

$\mathrm{p}>0.05$ non significant, NS

Fisher's exact test

\begin{tabular}{|c|c|c|c|c|}
\hline \multirow{2}{*}{\multicolumn{2}{|c|}{ Independent Variable }} & \multicolumn{2}{|l|}{ OHI-S } & \multirow{2}{*}{ p-value } \\
\hline & & \multirow{2}{*}{$\begin{array}{l}\text { Good } \\
\mathrm{I}(\mathrm{I} 4.5 \%)\end{array}$} & \multirow{2}{*}{$\begin{array}{l}\text { Fair And Poor } \\
65(85.5 \%)\end{array}$} & \\
\hline & upto I 5 Year & & & \\
\hline Age & 16- 20 Years & $56(29.2 \%)$ & $136(70.8 \%)$ & 0.0 \\
\hline \multirow{2}{*}{ Gender } & Male & $62(24.3 \%)$ & $193(75.7 \%)$ & \multirow{2}{*}{$0.32(\mathrm{NS})$} \\
\hline & Female & $5(38.5 \%)$ & $8(61.5 \%)$ & \\
\hline \multirow{2}{*}{ Education } & Primary Level & $14(\mid 2.0 \%)$ & $103(88.0 \%)$ & \multirow{2}{*}{$<0.001 *$} \\
\hline & More Than Primary Level & $53(35.1 \%)$ & $98(64.9 \%)$ & \\
\hline \multirow{2}{*}{ Length of Stay } & Up to 2 Months & $46(26.4 \%)$ & $128(73.6 \%)$ & \multirow{2}{*}{$0.55(\mathrm{NS})$} \\
\hline & Up to 6 Months or more & $2 \mathrm{I}(22.3 \%)$ & $73(77.7 \%)$ & \\
\hline \multirow{2}{*}{ Type OfVisit } & First Offender & $63(26.5 \%)$ & $175(73.5 \%)$ & \multirow{2}{*}{$0.17(\mathrm{NS})$} \\
\hline & Repeat Offender & $4(13.3 \%)$ & $26(86.7 \%)$ & \\
\hline
\end{tabular}

Table 6 Distribution of oral hygiene status of the subjects in relation to oral hygiene practices

\begin{tabular}{|c|c|c|c|c|}
\hline \multirow{2}{*}{ Independent Variable } & & \multicolumn{2}{|l|}{ OHI-S } & \multirow{2}{*}{ p-value } \\
\hline & & Good & Fair And Poor & \\
\hline \multirow{2}{*}{ Brushing Aid Used For Cleaning Teeth } & Tooth brush & $59(25.9 \%)$ & $169(74.1 \%)$ & \multirow{2}{*}{$0.55(\mathrm{NS})$} \\
\hline & Other & $8(20.0 \%)$ & $32(80.0 \%)$ & \\
\hline \multirow{2}{*}{ Material Used for Cleaning Teeth } & Tooth powder & $15(24.6 \%)$ & $46(75.4 \%)$ & \multirow{2}{*}{$1.00(\mathrm{NS})$} \\
\hline & Toothpaste and other & $52(25.1 \%)$ & $155(74.9 \%)$ & \\
\hline \multirow{2}{*}{ Frequency of brushing } & Once daily & $55(26.3 \%)$ & I54(73.7\%) & \multirow{2}{*}{0.39 (NS) } \\
\hline & Twice Daily Or More & $12(20.3 \%)$ & $47(79.7 \%)$ & \\
\hline \multirow{3}{*}{ Duration of brushing } & $1-2 \mathrm{~min}$ & $\mathrm{II}(\mathrm{I} 5.1 \%)$ & $62(84.9 \%)$ & \multirow{3}{*}{$0.05(\mathrm{NS})$} \\
\hline & $3-4 \mathrm{~min}$ & $13(3 \mid .7 \%)$ & $28(68.3 \%)$ & \\
\hline & $5 \mathrm{~min}$ or more & $43(27.9 \%)$ & I I I(72. I\%) & \\
\hline \multirow{2}{*}{ Method of Brushing } & Horizontal & $65(25.0 \%)$ & $195(75.0 \%)$ & \multirow{2}{*}{$1.00(N S)$} \\
\hline & Other & $2(25.0 \%)$ & $6(75.0 \%)$ & \\
\hline
\end{tabular}

Table 7 Periodontal status of the subjects in relation to age groups $*_{p}<0.05$ statistically significant $\mathrm{p}>0.05$ non significant, NS

\begin{tabular}{|c|c|c|c|c|c|c|}
\hline Age & & Healthy & Bleeding & Calculus & Shallow Pocket & Deep Pocket \\
\hline \multirow[t]{3}{*}{ Up to I 5 Year } & Mean(SD) & $3.58(1.60)$ & $0.14(0.68)$ & $2.22(I .52)$ & $0.01(. I I)$ & $0.0 \mathrm{I}(0 . \mathrm{II})$ \\
\hline & Median(QI-Q3) & $4(3.25-4)$ & $0(0-0)$ & $2(2-2)$ & $0(0-0)$ & $0(0-0)$ \\
\hline & Mean(SD) & $3.84(1.27)$ & $0.04(.25)$ & $2.10(1.25)$ & $0.01(0.07)$ & $0.02(0.28)$ \\
\hline 16- 20 Years & Median(QI-Q3) & $4(4-4)$ & $0(0-0)$ & $2(2-2)$ & $0(0-0)$ & $0(0-0)$ \\
\hline \multirow{2}{*}{ Mann Whitney $U$ test } & U statistic & 6947.50 & 7096.00 & 7250.00 & 7238.00 & 7238.50 \\
\hline & $\mathrm{P}$-value & $0.49(\mathrm{NS})$ & $0.26(\mathrm{NS})$ & $0.92(\mathrm{NS})$ & 0.49 (NS) & 0.50 (NS) \\
\hline
\end{tabular}

Table 8 DMFT scores of the subjects in relation to age groups ${ }^{*} \mathrm{p}<0.05$ statistically significant

$\mathrm{p}>0.05$ non significant, NS

\begin{tabular}{llllll}
\hline Age & & DT & MT & FT & DMFT \\
\hline Up to I5 Year & Mean(SD) & $0.57(I . I I)$ & $0.04(. I 9)$ & 0.00 & $0.55(I . I 3)$ \\
& Median(QI-Q3) & $0(0-I)$ & $0(0-0)$ & $0(0-0)$ & $0(0-I)$ \\
I6- 20 Years & Mean(SD) & $0.49(0.98)$ & $0.04(0.20)$ & $0.0 I(0.07)$ & $0.5 I(0.97)$ \\
& Median(QI-Q3) & $0(0-I)$ & $0(0-0)$ & $0(0-0)$ & $0(0-I)$ \\
Mann Whitney U test & U statistic & 7213.00 & 7280.00 & 7258.00 & 7224.50 \\
& P-value & $0.85(\mathrm{NS})$ & $0.93(\mathrm{NS})$ & $0.52(\mathrm{NS})$ & $0.87(\mathrm{NS})$ \\
\hline
\end{tabular}

Citation: Pallavi P,Amith HV, Kamath V, et al.Assessment of oral hygiene, periodontal status, dentition status and treatment needs among detainees in juvenile detention centres, of Madhya Pradesh.J Dent Health Oral Disord Ther. 2018;9(5):4I7-426. DOI: 10.15406/jdhodt.2018.09.004I9 
Table 9 Distribution of teeth missing due to caries, missing due to any other reason and trauma in relation to age groups $* p<0.05$ statistically significant

$p>0.05$ non significant, NS

\begin{tabular}{|c|c|c|c|c|}
\hline Age & & Missing due to Caries & Missing due to Any other reason & Trauma \\
\hline \multirow[t]{2}{*}{ Up to 15 Years } & Mean(SD) & $0.03(.16)$ & $0.01(.1 \mathrm{I})$ & $0.04(.25)$ \\
\hline & Median(QI-Q3) & $0(0-0)$ & $0(0-0)$ & $0(0-0)$ \\
\hline \multirow{2}{*}{ 16-20Years } & Mean(SD) & $0.04(0.18$ & $0.01(0.10)$ & $0.04(0.20)$ \\
\hline & Median(QI-Q3) & $0(0-0)$ & $0(0-0)$ & $0(0-0)$ \\
\hline \multirow{2}{*}{ Mann Whitney $U$ test } & U statistic & 7222.00 & 7276.00 & 7188.00 \\
\hline & p-value & $0.67(\mathrm{NS})$ & $0.84(\mathrm{NS})$ & $0.56(\mathrm{NS})$ \\
\hline
\end{tabular}

Table 10 Distribution of juvenile detainees according to treatment need

\begin{tabular}{llll}
\hline Treatment need & Present & absent & Mean (SD) \\
\hline None & $86(32.1 \%)$ & $182(67.9 \%)$ & $28.10(1.8 I)$ \\
Preventing Caries Arresting Care & 0 & $268(100 \%)$ & 0 \\
Fissure Sealant & 0 & $268(100 \%)$ & 0 \\
One surface filling & $63(23.5 \%)$ & $205(76.5 \%)$ & $0.40(0.90)$ \\
Two or more surface filling & $13(4.9 \%)$ & $255(95.1 \%)$ & $0.06(0.29)$ \\
Crown for any reason & 0 & $268(100 \%)$ & 0 \\
Veneer or laminates & 0 & $268(100 \%)$ & 0 \\
Pulp care Restoration & $15(5.6 \%)$ & $253(94.4 \%)$ & $0.06(0.27)$ \\
Extraction & $7(2.6 \%)$ & $261(97.4 \%)$ & $0.03(0.16)$ \\
Need for other Care(specify) & $8(3.0 \%)$ & $260(97.0 \%)$ & $0.03(0.17)$ \\
Need for other Care(specify) & 0 & $268(100 \%)$ & 0 \\
Not recorded & 0 & $268(100 \%)$ & 0 \\
\hline
\end{tabular}

Table I I Periodontal status of the subjects assessed by community periodontal index in relation to age, gender, education, length of stay and type of visit $*_{\mathrm{p}}<0.05$ statistically significant

$\mathrm{p}>0.05$ non significant, NS

Fisher's exact test

\begin{tabular}{|c|c|c|c|c|c|}
\hline \multirow{2}{*}{\multicolumn{2}{|c|}{ Independent variables }} & \multicolumn{3}{|c|}{ Highest - CPI score } & \multirow{2}{*}{ p-value } \\
\hline & & \multirow{2}{*}{$\begin{array}{l}\text { Healthy } \\
9(11.8 \%)\end{array}$} & \multirow{2}{*}{$\begin{array}{l}\text { Bleeding \& Calculus } \\
62(81.6 \%)\end{array}$} & \multirow{2}{*}{$\begin{array}{l}\text { Shallow \& Deep Pockets } \\
5(6.6 \%)\end{array}$} & \\
\hline \multirow{2}{*}{ Age } & Up to I 5 years & & & & \multirow{2}{*}{$0.01 *$} \\
\hline & 16- 20 years & $24(I 2.5 \%)$ & $130(67.7 \%)$ & $38(19.8 \%)$ & \\
\hline \multirow{2}{*}{ Gender } & Male & $29(11.4 \%)$ & $184(72.2 \%)$ & $42(16.5 \%)$ & \multirow{2}{*}{$0.12(\mathrm{NS})$} \\
\hline & Female & $4(30.8 \%)$ & $8(61.5 \%)$ & $\mathrm{I}(7.7 \%)$ & \\
\hline \multirow{2}{*}{ Education } & Primary Level & $8(6.8 \%)$ & $101(86.3 \%)$ & $8(6.8 \%)$ & \multirow{2}{*}{$<0.001 *$} \\
\hline & $\geq$ Primary Level & $25(16.6 \%)$ & $91(60.3 \%)$ & $35(23.2 \%)$ & \\
\hline \multirow{2}{*}{ Length of stay } & Up to 2 Months & $25(14.4 \%)$ & $122(70.1 \%)$ & $27(15.5 \%)$ & \multirow{2}{*}{$0.39(\mathrm{NS})$} \\
\hline & 6 Months or more & $8(8.5 \%)$ & $70(74.5 \%)$ & $16(17.0 \%)$ & \\
\hline \multirow{2}{*}{ Type of Visit } & First Offender & $31(13.0 \%)$ & $167(70.2 \%)$ & $40(16.8 \%)$ & \multirow{2}{*}{$0.42(\mathrm{NS})$} \\
\hline & Repeat Offender & $2(6.7 \%)$ & $25(83.3 \%)$ & $3(10.0 \%)$ & \\
\hline
\end{tabular}

Table I 2 Periodontal status of the subjects assessed by community periodontal index in relation to oral hygiene practices $*_{p}<0.05$ statistically significant

p>0.05 non significant, NS (Fisher's exact test)

\begin{tabular}{|c|c|c|c|c|c|}
\hline \multirow{2}{*}{\multicolumn{2}{|c|}{$\begin{array}{l}* p<0.05 \text { statistically significant } \\
\text { Highest - CPI score }\end{array}$}} & \multicolumn{3}{|c|}{ p>0.05 non significant, NS (Fisher's exact test) } & \multirow{2}{*}{$\begin{array}{l}\text { I } \mathbf{n} d \text { e p e } n d \text { e } n \mathbf{t} \\
\text { variables }\end{array}$} \\
\hline & & \multicolumn{2}{|l|}{ p-value } & \multirow{2}{*}{$\begin{array}{l}\text { Shallow Pocket \& } \\
\text { Deep Pocket } \\
38(16.7 \%)\end{array}$} & \\
\hline Healthy & Bleeding \& Calculus & $\begin{array}{l}\text { Shallow Pocket \& } \\
\text { Deep Pocket }\end{array}$ & $161(70.6 \%)$ & & \multirow[b]{2}{*}{$0.79(\mathrm{NS})$} \\
\hline & $\begin{array}{l}\text { Brushing Aid Used For } \\
\text { Cleaning Teeth }\end{array}$ & Tooth brush & $3 \mathrm{I}(77.5 \%)$ & $5(12.5 \%)$ & \\
\hline $29(12.7 \%)$ & $161(70.6 \%)$ & $38(16.7 \%)$ & $45(73.8 \%)$ & $12(19.7 \%)$ & \multirow[b]{2}{*}{0.23 (NS) } \\
\hline 0.79 (NS) & & Other & |47(7|.0\%) & $31(15.0 \%)$ & \\
\hline
\end{tabular}


Table Continued...

\begin{tabular}{|c|c|c|c|c|c|c|}
\hline \multirow[t]{2}{*}{$4(10.0 \%)$} & $3 \mathrm{I}(77.5 \%)$ & & $5(12.5 \%)$ & $150(7 \mid .8 \%)$ & $35(16.7 \%)$ & \multirow[b]{2}{*}{$0.68(\mathrm{NS})$} \\
\hline & $\begin{array}{l}\text { Material Used } \\
\text { Cleaning Teeth }\end{array}$ & for & Tooth powder & $42(71.2 \%)$ & $8(13.6 \%)$ & \\
\hline $4(6.6 \%)$ & $45(73.8 \%)$ & & $12(19.7 \%)$ & $59(80.8 \%)$ & $8(11.0 \%)$ & \\
\hline $0.23(\mathrm{NS})$ & & & Toothpaste and other & $27(65.9 \%)$ & $8(19.5 \%)$ & $0.35(\mathrm{NS})$ \\
\hline \multirow[t]{2}{*}{$29(14.0 \%)$} & $\mid 47(7 \mid .0 \%)$ & & $3 I(15.0 \%)$ & $106(68.8 \%)$ & $27(17.5 \%)$ & \\
\hline & . & & $\begin{array}{l}\text { Frequency } \\
\text { brushing }\end{array}$ & $\mid 86(7 \mid .5 \%)$ & $43(16.5 \%)$ & \multirow[t]{2}{*}{$0.28(\mathrm{NS})$} \\
\hline Once daily & $24(I I .5 \%)$ & & $\mid 50(7 \mid .8 \%)$ & $6(75.0 \%)$ & 0 & \\
\hline
\end{tabular}

Table I 3 Mean (SD) oral hygiene status of juveniles in detention centre in relation to gender, age, education, length of stay, type of visit, brushing aids used for cleaning teeth, material used for cleaning teeth, frequency of brushing and method of brushing

Mann Whitney $U$ test, ${ }^{*} P<0.05$ statistically significant,$P>0.05$ non significant, NS

\begin{tabular}{|c|c|c|c|c|c|}
\hline Independent variables & & $\mathbf{N}$ & Mean OHI-S & SD & p-value \\
\hline \multirow{2}{*}{ Gender } & Male & 255 & 1.57 & 0.68 & \multirow{2}{*}{$0.21(\mathrm{NS})$} \\
\hline & Female & 13 & 1.34 & 0.38 & \\
\hline \multirow{2}{*}{ Age } & Up to 15 years & 76 & 1.65 & 0.66 & \multirow{2}{*}{$0.10(\mathrm{NS})$} \\
\hline & $16-20$ years & 192 & 1.52 & 0.67 & \\
\hline \multirow{2}{*}{ Education } & Primary Level & 117 & 1.81 & 0.76 & \multirow{2}{*}{$0.001 *$} \\
\hline & $\geq$ Primary Level & $|5|$ & 1.36 & 0.51 & \\
\hline \multirow{2}{*}{ Length of stay } & Up to 2 months & 174 & 1.54 & 0.67 & \multirow{2}{*}{$0.5 \mathrm{I}(\mathrm{NS})$} \\
\hline & 6 months or more & 94 & 1.59 & 0.65 & \\
\hline \multirow{2}{*}{ Type of visit } & First Offender & 238 & 1.53 & 0.64 & \multirow{2}{*}{$0.06(\mathrm{NS})$} \\
\hline & Repeat Offender & 30 & 1.82 & 0.84 & \\
\hline \multirow{2}{*}{ Brushing Aid Used For Cleaning Teeth } & Tooth Brush & 228 & 1.56 & 0.64 & \multirow{2}{*}{0.72 (NS) } \\
\hline & Other & 40 & 1.55 & 0.81 & \\
\hline \multirow{2}{*}{ Material Used for Cleaning Teeth } & Tooth powder & 61 & 1.49 & 0.61 & \multirow{2}{*}{$0.3 \mathrm{I}(\mathrm{NS})$} \\
\hline & Toothpaste and other & 207 & 1.58 & 0.68 & \\
\hline \multirow{2}{*}{ Frequency of brushing } & Once daily & 209 & 1.54 & 0.65 & \multirow{2}{*}{0.25 (NS) } \\
\hline & Twice daily or more & 59 & 1.64 & 0.73 & \\
\hline \multirow{3}{*}{ Duration Of Brushing } & I-2 min & 73 & 1.68 & 0.67 & \multirow{3}{*}{$0.03 *$} \\
\hline & 3-4 min & 41 & $\mathrm{I} .40$ & 0.66 & \\
\hline & 5 min or more & 154 & 1.54 & 0.66 & \\
\hline \multirow{2}{*}{ Method of Brushing } & Horizontal & 260 & 1.57 & 0.67 & \multirow{2}{*}{$0.21(\mathrm{NS})$} \\
\hline & Other & 8 & 1.31 & 0.46 & \\
\hline
\end{tabular}

\section{Discussion}

Oral health is not just clean teeth. In other words, oral health refers to the health of our mouth and, ultimately supports and reflects the health of the entire body. ${ }^{12}$ Rules of health and well being applicable to common man has no exceptions on prisoners / prison inmates in prisons or juvenile homes. Though such people may have a different lifestyle because of the environment in which they live, maintaining a good oral hygiene is an integral part of being healthy. To protect juvenile detainees, "The Juvenile Justice (Care and Protection of Children) Act 2000" was lays down the primary law for not only the care and protection of the children but also for the adjudication and disposition of matters relating to children in conflict with law. In literature, there have been very few studies carried out on the oral health status of juvenile detainees. The present study is an attempt, carried out with the intention to provide systematic information and assess the impact of various demographic variables and lifestyle on the oral hygiene and periodontal status, dentition status and treatment needs among the detainees in juvenile detention centres of Madhya Pradesh state. In present study males were more (95.1\%) than females (4.9\%) which were similar to Anil Agrawal et al. ${ }^{1}$ (2011) study on detainees of the Juvenile Detention Center in Udaipur, and Veera Reddy et al. ${ }^{5}$ (2012) study which was on prison inmates of central jail, Karnataka. The reason may be male crime rate is more than female crime rate and also females are less aggressive than males. Majority of detainees i.e., 228(85.1\%) used tooth brush which in contrast to Anil Agrawal et al study in 2011 where only 57(25.6\%) were using toothbrush. The present study finding was in consistent with Nobile CGA et al. ${ }^{13}$ which was on male prisoners in Italy stated that $96 \%$ of the population in their study used tooth brush. Renuka $\mathrm{G}$ et al. ${ }^{14}$ in 2014 conducted study among the prisoners of Dharwad city and they observed that majority of subjects $176(68.75 \%$ ) cleaned their teeth with toothbrush which is consistent with our study. 
Most of detainees $207(77.2 \%$ ) brushed their teeth once a day for more than 5minutes $154(57.5 \%)$ and most of them were using horizontal method 260(97.0\%) for cleaning teeth. The reason may be they were not taught about the basic correct oral hygiene practices.

Majority of juvenile detainees 264(98.5\%) were not using mouthwash; the reason may be mouthwash were not available to them and also most of them had not heard of mouthwash usage for maintenance of oral hygiene. No information regarding this aspect was found in the existing literature. In the present study more than half of the detainees $167(62.3 \%$ ) had consumed tobacco in any form, but majority of them consumed smokeless tobacco 123(45.9\%). This finding was in contrast to EA Akaji, N Folaranmi ${ }^{15}$ study on Nigerian detainees where $(52.2 \%)$ were current tobacco users and most of them $(81.7 \%)$ were consuming tobacco in the form of cigarette/smoked form. The present study findings were in contrast to Madhya Pradesh $2007-2008$ survey, ${ }^{16}$ according to which $47 \%$ of population in Madhya Pradesh used tobacco in any form (i.e. smoking or smokeless). The reason behind this first is the racial differences and second in Madhya Pradesh smokeless tobacco usage is more prevalent as compared to smoked form. Our study findings regarding adverse habits were consistent with Renuka G et al. ${ }^{14}$ study in 2014 conducted study on prisoners of Dharwad, in which about $40-60 \%$ of study subjects who were in the age group of 18 to 27 years had adverse habits of tobacco chewing or smoking, and most of the participants $(57.3 \%)$ were smokeless tobacco user. In present study most of the juvenile detainees $231(86.2 \%)$ had the habit of smoking for less than 1month, and out of 268 juvenile detainees $84(31.3 \%)$ used smokeless tobacco for more than 12 months. These findings were in contrast to Muni Kumar Sode ${ }^{8}$ conducted study on Prison Inmates of Nellore District in Andhra Pradesh in 2011, where maximum duration reported was $1-5 y$ ears for both form of tobacco. The reason behind this was, the age group in our study was juvenile detainees (5-20years) while in Sode's study it was from 18-78years. In present study majority of juvenile detainees $133(49.6 \%)$ had chewed $1-5$ pouches per day. This finding was in contrast to Muni Kumar Sode ${ }^{8}$ where most of detainees (12\%) were consuming 5-10 packets per day. Reason for this may be that as the age increases, frequency of consumption increases because of the nicotine dependence developed in the subject and also juveniles are restrained from consuming tobacco. In our study it was found that $250(93.3 \%)$ juvenile detainees never visited a dentist previously and very few of them-18(6.7\%) visited dentist for treatment of their dental problem, which in contrast to Anup N et al. ${ }^{11}$ The reason may be our study was on juvenile detainees and most of them ignore their dental problem until it becomes unbearable, while in Anup $\mathrm{N}$ et al. ${ }^{11}$ study age group of the participant was from 18-85years it was the age group when subjects visit dentist for periodontal or some other kind of dental problems. In our study, very few 7 (2.6\%) had poor oral hygiene, in contrast to Anil Agrawal study where 73(32.8\%) had poor oral hygiene status. This shows that there is improvement in the oral hygiene status of detainees over the years which may be because government is providing toothbrush and toothpaste to the detainees in the juvenile centres. In the present study, most of the subjects had calculus $230(85.8 \%)$ which was in accordance with the studies conducted by Varenne et al. ${ }^{17}$ on children and adults in urban and rural areas of Burkina Faso, Africa, Veera Reddy ${ }^{5}$ (2012) conducted study among inmates in central jails of Karnataka, AO Umoh \& CC Azodo ${ }^{18}$ and also with Anil Agrawal. ${ }^{1}$

In the present study $33(12.3 \%)$ subjects had healthy gingiva, $2(.7 \%)$ had bleeding, $1(.4 \%)$ had pocket $4-5 \mathrm{~mm}, 2(.7 \%)$ had pocket
$6 \mathrm{~mm}$ or more, in contrast to $\mathrm{AO}$ Umoh and $\mathrm{CC}$ Azodo ${ }^{18}$ conducted study among Adult Male Population in Benin City, Nigeria where, $9.2 \%$ had healthy gingiva, $13.9 \%$ had $4-5 \mathrm{~mm}$ periodontal pockets (code 3 ), while $1.5 \%$ had $\pm 6 \mathrm{~mm}$ periodontal pockets (code 4 ). The reason can be, in our study juvenile detainees were the subjects while in AO Umoh ${ }^{18}$ study population the subjects were adult males. Also periodontal pockets are less common in juvenile as compare to adult. In our study, the difference in OHI-S scores among the different age groups was statistically significant $(\mathrm{p}=0.01)$ similar to the findings of Anil Agrawal. ${ }^{1}$ In the present study, significant statistical difference was found between education and oral hygiene status with $p$ value $<0.001$. This finding was in accordance with study and Anil Agrawal ${ }^{1}$ study where higher education has been associated with a better level of oral hygiene. In our study, for the age group up to 15years of age, the mean number of healthy sextants was 3.58. Almost similar findings were reported in National oral health survey of Madhya Pradesh (2004) by Bali et al. ${ }^{19}$ where mean number of healthy sextant was 3.0.In the present study mean no. of sextants were 0.14 for bleeding from tissue on probing, 2.22 for calculus and 0.01 for shallow and deep pockets. These findings were in contrast to National oral health survey of Madhya Pradesh (2004) by Bali et al. ${ }^{19}$ where values were $1.8,1.1$, and 0.0 respectively. The reason for this higher calculus can be poorer oral health knowledge, negative attitude to oral health and less importance to oral and general health among the detainees as compared to general population. In present study mean number of decayed teeth for up to 15 years age group weas $0.57(\mathrm{DT})$, missing teeth was 0.04(MT), there were no filled teeth (FT) and mean DMFT were 0.55 . These findings were in contrast to National oral health survey of Madhya Pradesh (2004) by Bali et al. ${ }^{19}$ where DT were 1.8 in 5years age group, 1.7 in 12years, 2.3 in 15years age group. While the mean DMFT for 5years, 12 years and 15years age group were 1.9, 1.8 and 2.3 respectively.In present study mean DMFT for $16-20$ years age group was 0.51 which is almost similar to Karanprakash Singh ${ }^{13}$ study which was on Prison Setting at Ferozepur City, where mean DMFT was 0.93. Present finding was in contrast to Anup N et al. ${ }^{11}$ study where the mean DMFT was 4.79. Nobile CGA et al. ${ }^{13}$ observed a mean DMFT score of 9.8. Present study results are also not similar to other studies conducted by ME Salive and Carolla JM ${ }^{20}$ study (1989) which was on male inmates in a state prison system, who reported a mean DMFT of 10.5 in their study subjects. . Veera Reddy et al. ${ }^{5}$ in his study on inmates in Central Jail in Karnataka obtained a mean DMFT of 5.26. The reason for low mean DMFT in our study may be attributed to good utilization of preventive and therapeutic dental services. Also whenever detainees report any oral problem, the matron in charge of that centre takes the detainees to nearest government dental hospital for treatment. There is improvement in availability of dental personnel for juvenile detainees. In the present study, for the age group of up to 15 years, mean number of teeth missing due to caries was 0.03 and missing due to any other reason was 0.01 . This was in contrast National oral health survey of Madhya Pradesh (2004) by Bali et al. ${ }^{19}$ where mean number of teeth missing due to caries was 0.1 in 12 years age group. There were no teeth missing due to caries \& missing due any other reason in 15 years age group.

In the present study, out 268 detainees, $86(32.1 \%)$ required no treatment, while $182(67.9 \%)$ required treatment. Sixty three $(23.5 \%)$ of juveniles required one surface restoration. Two or more surface restoration was required by $13(4.9 \%)$ of them. None of them needed crown, veneer or laminates. Fifteen $(5.6 \%)$ juveniles needed pulp care / restoration. Extractions were needed in case of $7(2.6 \%)$ juveniles, need for other care was found in $8(3.0 \%)$ of the subjects. 
These finding were in contrast to Renuka G. et al. ${ }^{14}$ study where, 172 $(67.19 \%)$ subjects needed one surface filling, $48(18.75 \%)$ subjects needed two or more surface restoration, 27 (10.55\%) subjects needed pulp care, and $81(31.64 \%)$ subjects needed extraction. These findings were also in disagreement with Anup $\mathrm{N}$ et al. ${ }^{11}$ study were Out of 870 inmates, 413(47.5\%) needed one surface restoration and $476(54.7 \%)$ required two or more surface restoration. Whereas 256(29.4\%) inmates need pulp care, 355(40.8\%) needed extraction, and $460(52.9 \%)$ required prosthetic replacement. The reason for the differences in both the studies being the age groups involved was mostly above $18-65$ years and above, whereas in the present study age group was 5-20years. Present study finding indicates that overall treatment need of juvenile was quite low as compared to Renuka G et al. ${ }^{14}$ and Anup $\mathrm{N}$ et al. ${ }^{11}$ study. There was a significant difference between age and CPI scores with $\mathrm{p}$ value 0.01 , which is in agreement with Mundoor Manjunath Dayakar et al. ${ }^{21}$ and Anil Agrawal ${ }^{1}$ study where, the correlation between the CPI score and age was highly significant $(p=0.002) \&(p=.0 .044)$ receptively. Which means age is an associated factor for periodontal disease. Significant difference between level of education and periodontal status with $p$ value 0.001 was noted in the present study, which is in disagreement with Anil Agrawal $^{1}$ study. It indicates that education does affect the periodontal status. Low educational attainment adversely affects different forms of hygiene, namely bodily, oral and environmental, as poorer oral hygiene, higher plaque and calculus scores were evident among lower educationally attained participants in comparison with higher educational attainment participants. In the present study, it was found that other variables like Gender, Length of stay and type of visit were not significantly associated with CPI scores. These findings were in accordance with Anil Agrawal et al. ${ }^{1}$ study. Oral hygiene practices which includes Brushing aid used for cleaning teeth, Material used for cleaning teeth, frequency of brushing, method of brushing were not significantly associated with CPI scores. These findings were consistent with Anil Agrawal et al. ${ }^{1}$ study. In our study education level and duration of brushing were significantly associated with oral hygiene status. These findings are in accordance with Anil Agrawal et al. ${ }^{1}$ study. This means level of education and duration of brushing affects the oral hygiene status. Commonly it was seen that persons who had good education level maintained a good oral hygiene. Remaining Independent variables that is gender, age, length of stay, type of visit, brushing aids used for cleaning teeth, material used for cleaning teeth, frequency of brushing and method of brushing were not significantly associated with oral hygiene status in our study which were in contrast to Anil Agrawal et al. ${ }^{1}$ It is difficult to compare the prevalence of oral diseases and treatment needs of the present study subjects with epidemiological surveys done in several other countries as there is a difference in the demographic characteristics of the study populations; including ethnicity, age, socioeconomic status, medical, and judicial systems of the various countries. As a result of such differences, results of the studies were expected to vary substantially. Taking into consideration the multifactorial influence on oral health status of the present detainee population, oral health promotion and intervention programs should be targeted and concentrated towards these risk groups. This was a pioneer study in Madhya Pradesh. Further study should be done on this population, because they are most of the time neglected.

\section{Acknowledgements}

None.

\section{Conflict of interest}

The author declares that there is no conflict of interest.

\section{References}

1. Anil Agrawala, Nagesh Bhat, Srinath Shetty, et al. Oral Hygiene and Periodontal Status among Detainees in a Juvenile Detention Center, India. Oral Health Prev Dent. 2011;9:281-287.

2. Adenwalla M. Child protection and juvenile justice system for juvenile in conflict with law. $1^{\text {st }}$ ed. Childline foundation India: Plan International; 2006:10-26.

3. Dhanker K, Ingle NA, Kaur N, et al. Oral Health Status and Treatment Needs of Inmates in District Jail of Mathura City - A Cross Sectional Study. J Oral Health Comm Dent. 2013;7(1):24-32.

4. Berkman A. Prison health: the breaking point. Am J Public Health 1995;85(12):1616-1618

5. Veera Reddy, Chadlavda Venkanta Kondareddy, Sunitha Siddanna, et al. A survey on oral health status and treatment needs of life-imprisoned inmates in central jails of Karnataka, India. International Dental Journal. 2012;62:27-32.

6. Clare JH. Dental health status, unmet needs and utilization of services in a cohort of adult felons at admission and after 3 years' incarceration. $J$ Correct Health Care. 2002;9:65-76.

7. Heidari E, Dickinson C, Wilson R, et al. Oral health of remand prisoners in HMPBrixton, London. British Dental Journal. 2007;1-6.

8. Muni Kumar Sode, Nusrath Fareed, Shanthi M, et al. Oral Health Status and Treatment Needs amongst Prison Inmates of Nellore District in Andhra Pradesh. Journal Of The Indian Association Of Public Health Dentistry. 2011;18:1-4.

9. Singh Sanjay Kumar, Saha Sabyasachi, Jagannath GV, et al. Denttition status and treatment needs in prisoners of lucknow-a cross sectional study. Indian Journal of Contemporary Dentistry. 2014;2(1):158-162.

10. McGrath C. Oral health behind bars: a study of oral disease and its impact on the life quality of an older prison population. Gerodontology. 2002;19(2):109-114.

11. Anup N, Gautam Biswas, Preeti Vishnani, et al. Oral Health Status and Treatment Needs Of Inmates in District Jail of Jaipur City - A Cross Sectional Study. IOSR Journal of Nursing and Health Science. 2014;3(3):22-31.

\section{VADM Regina M Benjamin. Public Health Reports. 2010;125:158-159.}

13. Nobile CG, Fortunato L, Pavia M, et al. Oral health status of male prisoners in Italy. International Dental Journal. 2007;57(1):27-35.

14. Renuka G Nagarale, Girish Nagarale, Preetha J Shetty, et al. Oral health status and treatment need of prisoners of Dharwad, India. International Journal of Dental and Health Sciences. 2014;1(6):851-860.

15. Akaji EA, Folaranmi N. Tobacco use and oral health of inmates in a Nigerian prison. Nigerian Journal of Clinical Practice. 2013;16(4):473477 .

16. Integrated Disease Surveillance Project (IDSP) Non Communicable Disease Risk Factor Survey. 2007-08 Madhya Pradesh. 1 -61.

17. Benoît Varenne, Poul Erik Petersen, Seydou Ouattara. Oral health status of children and adults in urban and rural areas of Burkina Faso, Africa. International Dental Journal. 2004;54:83-89.

18. Umoh A, Azodo C. Association between Periodontal Status, Oral Hygiene Status and Tooth Wear among Adult Male Population in Benin City, Nigeria. Ann Med Health Sci Res. 2013;3(2):149-154. 
19. Bali Rk, Mathur VR, Talwar PP, et al. Mapping of Fluride levels. In: National Oral Health Survey and Fluoride mapping 2002-2003 Madhya Pradesh, DCI, New Delhi. 2004.

20. Salive ME, Carolla JM, Brewer TF. Dental health of male inmates in a state prison system. J Public Health Dent. 1989 Spring;49(2):83-86.

21. Mundoor Manjunath Dayakar, Shivprasad D, Prakash G Pai. Assessment of periodontal health status among prison inmates: A cross-sectional survey. Journal of Indian Society of Periodontology. 2014;18(1):74-77. 